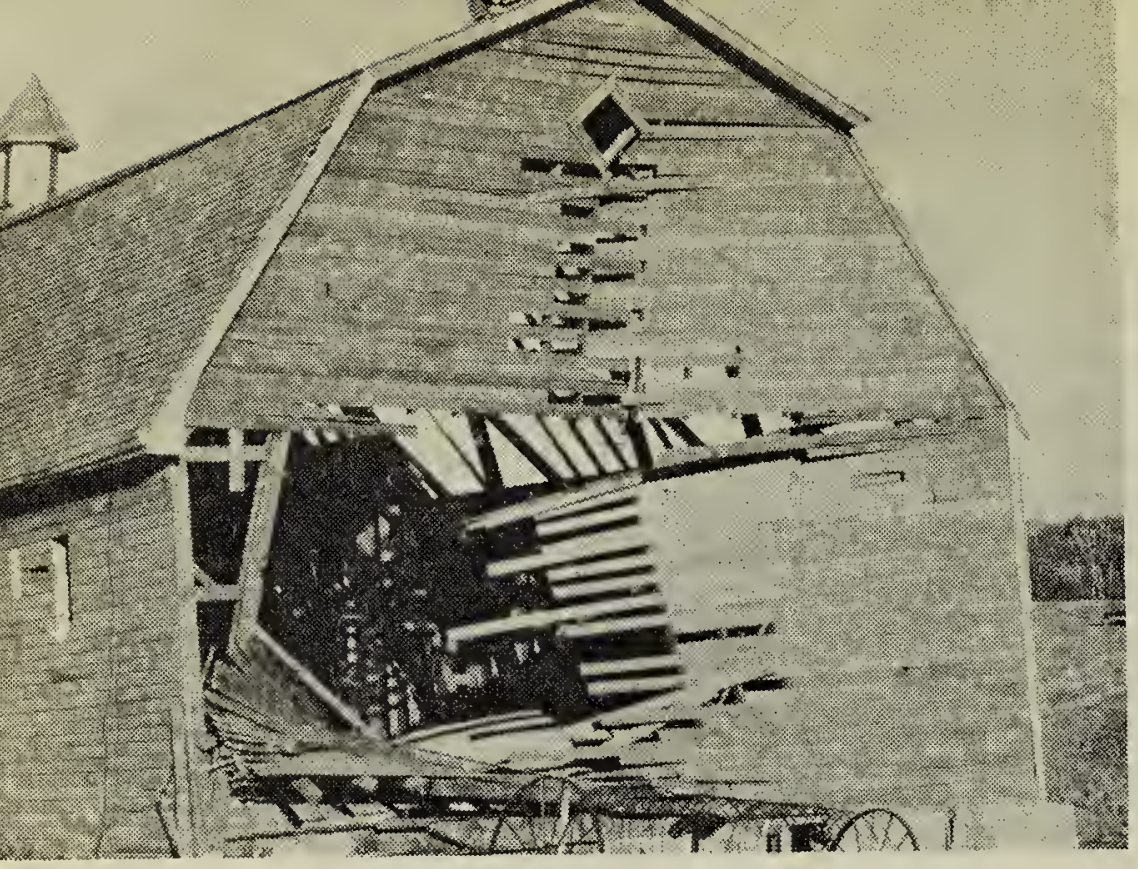

\title{
Hail Damage
}

\author{
in the
}

July 17 Storm

Barn damaged by hail

and wind during the

July storm, 10 miles

northeast of Moose

Jaw.

Cat-tails cut down by hail, 12 miles southwest of Regina Beach.

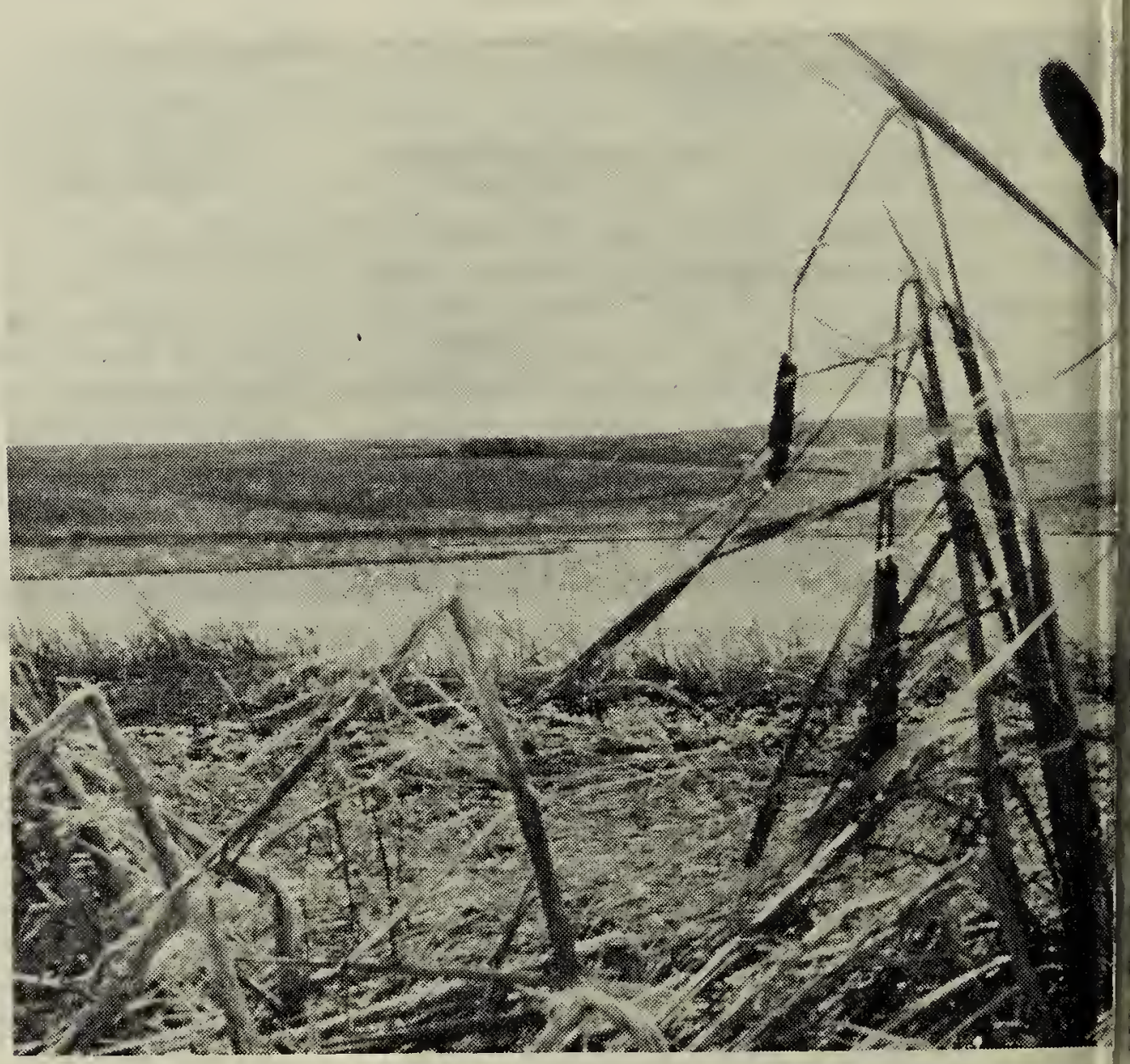

Dr. R. Nero examines a crop completely destroyed by hail on a farm northeast of Moose Jaw. 
